\title{
Reseña del Homenaje a Carmen Miró*
}

\section{Coralia Herrera y Liliana Giraldo**}

De los momentos más importantes que se tiene para reunirse con los amigos y compañeros es cuando se celebra algo. Ése es el caso del merecido homenaje que el Centro de Estudios Demográficos, Urbanos y Ambientales (CEDUA) de El Colegio de México le rindió a Carmen Miró el 1 de septiembre del presente año, el cual fue inolvidable tanto para Carmen como para el nutrido grupo de asistentes. Este homenaje fue apoyado por la Asociación Latinoamericana de Población (ALAP) y la Sociedad Mexicana de Demografía (Somede).

El acto estuvo moderado por Susana Lerner y contó con la participación del presidente de El Colegio de México, Javier Garciadiego; el secretario general, Manuel Ordorica, y el director del CEDUA, José Luis Lezama. También estuvieron presentes los colegas, alumnos, familiares y amigos que han acompañado a Carmen en su carrera profesional.

En el marco de este ambiente de fraternidad, la homenajeada recibió una pequeña réplica de la escultura Semina Motuum del artista Luis Palacios Kaim, misma que se ubica en la entrada de El Colegio. De acuerdo con Garciadiego, "el nombre de esta escultura es afortunadísimo para este premio pues significa la semilla inicial que ha puesto en movimiento algo: En el campo de la demografía latinoamericana, Carmen Miró representa esa semilla”. Asimismo Garciadiego destacó que con el homenaje a tan prestigiosa demógrafa, El Colegio de México -que en múltiples ocasiones ha sido receptor de reconocimientos- inicia una nueva etapa en la que también busca reconocer y agradecer el esfuerzo de personas que desde diferentes disciplinas o especialidades han contribuido y contribuyen a enriquecer el quehacer de la institución en su conjunto.

Desde luego en este homenaje se hizo alusión a la tarea realizada por Carmen Miró, su contribución a la formación de los primeros demógrafos en América Latina, sus aportes a la investigación demográfica, su apoyo en la creación de instituciones de enseñanza e investigación, y su actitud crítica a las políticas de población. Para Manuel

* Reseña del Homenaje a Carmen Miró, realizado en El Colegio de México, 1 de septiembre de 2006.

** Estudiantes de la maestría en Demografía, CEDUA, El Colegio de México.

ESTUDIOS DEMOGRÁFICOS Y URBANOS, VOL. 22, NÚM. 2 (65), PP. 493-499 
Ordorica "ella siempre ha demostrado ser creyente en que la ciencia y el método pueden y deben contribuir al desarrollo económico, social y político. Sus preocupaciones no se han limitado al plano teórico, sino que en todo momento ha buscado encontrarse en el campo de las políticas sociales". De esta manera y sin más preámbulo se distinguió a Carmen Miró como el personaje latinoamericano más conocido en el mundo de los estudios de población.

Por su parte, José Luis Lezama indicó que Carmen Miró debe ser reconocida por "sus grandes aportaciones a la constitución de la demografía como ciencia, y a la emergencia de la población como objeto de reflexión y de políticas públicas en América Latina”. También destacó el entusiasmo que el conjunto del CEDUA mostró para la realización de este homenaje, así como el especial empeño que pusieron sus organizadoras: Brígida García, Susana Lerner, Ivonne Szasz y Silvia Giourguli.

Lo que Carmen Miró significa para la demografía latinoamericana, su contribución a este campo de conocimiento, y lo que ha sido su trayectoria profesional, fueron los aspectos que se resaltaron en la segunda parte del homenaje. En ella participaron reconocidos investigadores en esta disciplina, quienes han estado cercanos a la trayectoria de Carmen: Alfredo Lattes, del Centro de Estudios de Población (Cenep) de Argentina; José Miguel Guzmán, del Área de Población y Desarrollo del Centro Latinoamericano y Caribeño de Demografía (Celade); Alejandro Canales, presidente de la Asociación Latinoamericana de Población (ALAP); María Coleta Oliveira, de la Universidad de Campinas, quien también participó en representación de la comunidad de demógrafos de Brasil, y Brígida García, de El Colegio de México. El homenaje se convirtió en un espacio de reflexión colectiva en el que se discutió sobre la evolución del pensamiento sobre población en América Latina, así como el estado del ejercicio profesional de la demografía y sus perspectivas a futuro. Ambos temas fueron vinculados con la destacada trayectoria de Carmen Miró.

Alfredo Lattes reflexionó sobre la historia del pensamiento en población en la región, dando cuenta que dicha historia es la suma de muchos esfuerzos para construir dos sistemas muy articulados entre sí. El primero de ellos es el conceptual que incluye hipótesis, teorías, técnicas, datos y estilos de investigación, y el otro, un sistema concreto cuyos componentes hacen investigación y docencia: equipos de investigación, unidades documentales, redes de intercambio y otros recursos. Citando a Daniel Rodríguez, Lattes indicó que es posible identifi- 
car tres etapas por las que han pasado los estudios sobre población: la primera, que va desde finales de los años cincuenta hasta finales de los sesenta, se caracteriza por la orientación técnica y descriptiva; la segunda etapa, de principios de los años setenta a inicios de los ochenta, se caracteriza por la orientación científica explicativa; la tercera, vinculada al trabajo en los últimos años, deviene de la necesidad y afán de revisar lo que se ha hecho, y de discutir permanentemente la problemática metodológica y técnica en general, es decir, la postura crítica.

En este sentido Lattes resaltó la importancia del trabajo de Carmen Miró y su aporte a los dos sistemas a lo largo de esas etapas por las que ha pasado el pensamiento latinoamericano; se refirió a las reflexiones y escritos realizados sobre el porqué de las políticas de población en América Latina en los entretiempos que le van dejando sus clases, a su complicada gestión institucional, y a uno que otro reto a un investigador o becario perezoso. Este investigador también subrayó que no hay dimensión que pueda escapar a Carmen en su visión sistemática de las sociedades latinoamericanas y caribeñas.

José Miguel Guzmán resaltó la capacidad de Carmen Miró para sentar las bases para el desarrollo de la disciplina en América Latina, y centró su discusión en el presente y futuro de la demografía en la región. Indicó que no se trata de una tarea fácil dada la amplitud que ha tomado la disciplina como campo de estudio. Pese a los avances, advirtió, hay signos que no parecen alentadores debido a que la situación actual está marcada por varias paradojas: a) Si bien hay una discusión sobre las necesidades de información en los países y existe un mayor desarrollo en las fuentes de datos, no hay constancia de una mejora sustancial en la cobertura y calidad de los mismos, por ejemplo, la omisión censal y en algunos casos el subregistro de las estadísticas vitales. $b$ ) Hay avances del conocimiento en algunas áreas, sin embargo otras no han recibido mayor atención, por ejemplo, es necesario fortalecer el área de estudio de la mortalidad por causas violentas que en varios países está causando estragos en la población masculina, o los temas de envejecimiento no cuentan con recursos, ni interés suficiente como para garantizar la realización de estudios comparados. c) Se está en una etapa de cierta debilidad de la enseñanza en demografía, en un momento en que hay una mayor capacidad de producción de datos.

Guzmán también mencionó tres retos de la disciplina: 1) La necesidad de revalorizar el aporte de una mayor y mejor comprensión de los fenómenos demográficos para las políticas públicas, en particular 
las dirigidas a abatir la pobreza y la desigualdad; el objetivo es potenciar el aporte de la capacidad predictiva de la demografía como una contribución estratégica al desarrollo. 2) La necesidad de profundizar en el desarrollo teórico y metodológico de la demografía en su interacción con otras disciplinas; una manera de hacerlo es asirse de los grandes temas de la agenda actual, como el envejecimiento, las migraciones internacionales, los temas del medio ambiente. 3) La necesidad de abordar con mayor énfasis el tema de la ética y los derechos como base de las prácticas individuales y colectivas; estos aspectos no sólo ayudan a una mejor comprensión de las conductas individuales y cómo éstas generan resultados en la dinámica demográfica, sino también dan sentido a las propuestas de políticas que surjan del análisis demográfico. Finalmente, Guzmán exhortó a aprovechar el legado de Carmen Miró para enfrentar exitosamente los nuevos desafíos.

La capacidad de Carmen para articular el pensamiento social, el compromiso político y el análisis riguroso, la hace ser la representante del pensamiento crítico en América Latina. La reflexión de Alejandro Canales fue precisamente sobre la preocupación por articular un pensamiento crítico en la demografía; consideró que las contribuciones de Carmen Miró no sólo son académicas: son un estilo de vida, un compromiso social y político que mucha falta nos hace en los tiempos actuales. Su espíritu crítico está acompañado de su fortaleza política y social que le dan sentido y trascendencia a su obra. Esta articulación entre pensamiento social, compromiso político y capacidad de análisis es un legado que las nuevas generaciones debemos continuar: "las nuevas claves de la demografía han de surgir precisamente de la reflexión crítica de los procesos de cambio social y demográficos que actualmente se manifiestan en nuestras sociedades y en donde la desigualdad y la exclusión se tornan en una cuestión fundamental", agregó Canales. En concreto, propone la tesis de trasladar el discurso demográfico desde la tradicional relación población-desarrollo hacia un discurso de la demografía de la desigualdad; no se trata de dejar de pensar en el desarrollo sino de pensarlo en términos de la desigualdad. La demografía de la desigualdad advierte sobre la necesidad de pensar la estructura demográfica en el marco de las transformaciones sociales de la sociedad actual; el objetivo es "la comprensión y análisis de los contextos estructurales en los cuales las distintas categorías de diferenciación demográfica no sólo son categorías de desigualdad social, sino también mecanismos de constitución de sujetos desiguales". El contexto actual exige analizar a la población no tanto en función de su 
dinámica de crecimiento y sus componentes, sino en función de la estructura de relaciones entre individuos, géneros, etnias, generaciones y en general entre las distintas categorías demográficas.

En este homenaje también se hizo referencia a la relación entre el trabajo de Miró y diversos eventos políticos, económicos, sociales, institucionales y demográficos por los que atravesó no sólo su país de origen, sino la región latinoamericana y caribeña. Al respecto, María Coleta narró cómo en poco tiempo Carmen Miró fue conocida como:

la gran dama de la demografía latinoamericana, referida como mujer excepcional, merecedora de manifestaciones de aprecio, respeto y admiración. Su carácter crítico del pensamiento demográfico representa una marca de la identidad: identidad como región, identidad en cuanto a un continente pensante y activo en sus puntos de vista sobre los desafíos sociales que enfrentan nuestros países.

Por su parte, Brígida García, otra connotada demógrafa latinoamericana, resaltó la carrera profesional de Miró, de quien dijo: "ha sabido dar cuenta de la relación entre la evolución poblacional y el desarrollo económico y social en América Latina, y en sus escritos ha contribuido en el desarrollo del pensamiento poblacional en diferentes momentos históricos”. Destacó los planteamientos de Miró en torno a que "la solución de las crisis que enfrenta la región no pasa por medidas destinadas específicamente a modificar en forma directa las variables demográficas básicas (fecundidad, mortalidad y migración), aunque esa modificación podría coadyuvar a esa solución. El remedio es en primer lugar de tipo político”. Para Brígida García, Miró constituye un ejemplo palpable de lo que se puede lograr tanto en lo profesional como en lo personal cuando se tiene vocación y propósito de conocer y transformar la realidad.

Como lo hicieron saber todos los participantes, son diversos los perfiles de la trayectoria de Carmen Miró, pero uno de ellos marca un hito en la historia latinoamericana: el relacionado con su contribución al pensamiento sobre población y desarrollo de distintas instituciones a partir de los años sesenta. Tal fue su participación en el Centro Latinoamericano de Demografía (Celade), el antiguo Centro de Demografía y Economía (CEED) de El Colegio de México y del Centro de Estudios Demográficos (Cedem) de la Universidad de la Habana, así como su colaboración en instituciones y asociaciones como es el caso de FNUAP, IUSSP, PISPAL, Flacso y Celade, entre otras. Además de expre- 
sar palabras de afecto y agradecimiento, todos los comentaristas coincidieron en señalar que Carmen es una de las investigadoras a quien se le debe el impulso y desarrollo de la disciplina demográfica en América Latina.

Después de la reflexión colectiva y de haber conocido parte de la amplia trayectoria de Carmen, quien nació en Panamá en 1919, ésta se dirigió a los que le acompañaron, demostrando una vez más por qué se hace digna de este reconocimiento. Después de agradecer a todos los presentes por acompañarla en este importante momento, y de indicar que los trabajos presentados por sus colegas la estimulaban a la discusión y a la vez le generaban preocupación por todo lo que está aún por hacerse, rememoró algunos acontecimientos de su vida. Subrayó que deseaba compartir ese homenaje con otras personas que también hicieron una importante contribución para la creación y desarrollo del Celade con sede en Santiago de Chile. Esta institución fue el espacio que permitió a Carmen dar una de sus principales contribuciones al desarrollo de la demografía en la región, ya que por su medio se formaron los primeros demógrafos y se organizaron los principales centros de enseñanza e investigación en América Latina. Pese a su importante labor en Celade, narró que en 1970, después de cumplir doce años de estar dirigiendo esa institución, presentó su renuncia porque consideraba que "no era saludable para el desarrollo de una institución estar dirigida tantos años por una misma persona”, pues esa situación generaba cierto grado de complacencia que no dejaba lugar a la crítica. Consecuente con esta posición crítica, que es su sello de distinción, su separación del Celade sólo fue posible seis años después, porque en medio de este proceso se presentó el derrocamiento del presidente Allende (1973) y la subsecuente represión contra la población y las instituciones. El Celade como institución internacional también fue objeto de represión, por lo que Carmen consideró que en ese momento era imperativo permanecer al frente de la institución (en este caso poniendo en riesgo su vida, una muestra más de su entrega para el desarrollo de esta disciplina).

Otro recuerdo especial de Carmen fue su paso por México de 1976-1980, país al que llegó cuando asumió el reto de consolidar un proyecto cuyo objetivo era dirigir "a un grupo de profesionales de las principales regiones subdesarrolladas para realizar un estudio que analizara la situación, características y posible evolución futura de las poblaciones de estas regiones, y propusiera medidas de políticas para enfrentar los problemas sociales relacionados con el comportamiento 
demográfico de sus poblaciones". Este proyecto fue oportuno en un momento en que la demografía mundial estaba motivada por la paranoia del neomaltusianismo del crecimiento demográfico de los países en desarrollo. El Colegio de México fue su sede; además, la experiencia de Carmen fue aprovechada para la organización del programa de investigación del Centro de Estudios Demográficos. Para ella lo más importante de esta experiencia fue la impresionante discusión que se estimuló en la región, y recuerda con aprecio y admiración el apoyo recibido por personajes como Víctor Urquidi, Luis Unikel y Gustavo Cabrera.

La impresionante trayectoria de Carmen Miró permite constatar lo que la mayor parte de los expositores refirió: es un ejemplo de vida, de dedicación y entrega que contribuyó a cimentar y desarrollar la disciplina demográfica en América Latina. 